\title{
Artigos
}

Luciana Esmeralda Ostetto'

\section{Sobre a organização curricular da Educação Infantil: conversas com professoras a partir das Diretrizes Curriculares Nacionais²}

\begin{abstract}
Resumo: O artigo, produzido no contexto do diálogo com professoras que participavam de um curso de extensão na Universidade Federal de Alagoas, propõe uma reflexão sobre a organização curricular da Educação Infantil, das Diretrizes Curriculares Nacionais, analisando pressupostos e identificando bases para sua implementação. Delineando compreensões e consequências sobre os princípios éticos, políticos e estéticos anunciados no documento de 2009, destaca a importância da construção do Projeto Político Pedagógico (proposta pedagógica) nas instituições de Educação Infantil. Também levanta possibilidades para as linguagens expressivas no cotidiano educativo, ao traçar sentidos e significados sobre os eixos norteadores do currículo. Por fim, a necessária ampliação da sensibilidade de professoras e professores - no resgate da sua brincadeira, da sua expressão, das suas linguagens, do seu encantamento - é ressaltada como fundamental para que qualquer proposta de Educação Infantil conquiste êxito na qualidade socialmente referenciada do atendimento às crianças de zero a cinco anos.
\end{abstract}

Palavras-chave: Projeto Político Pedagógico; Linguagens Expressivas; Formação docente; Educação Estética.

\section{About the curricular organization of Early Childhood Education: conversations with teachers based on the National Curricular Guidelines}

\begin{abstract}
The article presents a new perception of the curricular organization of early childhood education based on the National Curricular Guidelines. In fact, this idea was created from a dialogue among professors in an extension course at Alagoas Federal University (Universidade Federal de Alagoas). In addition, it is also analyzed assumptions and bases are identified for the implementation of this new view. The paper also delineates understandings and consequences on the ethical, political and aesthetic principles announced in the 2009 document and highlights the importance of the construction of the pedagogical political project (pedagogical proposal) in the institutions of early childhood education. Actually, it is suggested hypotheses for expressive languages in the daily life of the educational system outlining senses and meanings on the axes guiding curriculum. Finally, it is observed the necessity in expanding the teacher's sensitivity, for example, in the rescue of her playing with children, her expression, her languages and her enchantment. All these elements are crucial for any proposal of early childhood education to achieve success in the socially referenced quality of children's care from zero to five years old.
\end{abstract}

Keywords: Political Pedagogical Project; Expressive Languages; Teacher Training; Aesthetic Education.

\footnotetext{
1 Doutora em Educação pela Unicamp. Professora da Faculdade de Educação da Universidade Federal Fluminense atua na graduação e na pós-graduação (mestrado e doutorado). E-mail: lucianaostetto@id.uff.br

2 Agradeço à Adriana Broering, pelo diálogo contínvo e pela interlocução sempre fecunda em torno de temas da Educação Infantil. Neste especial momento, grata por compartilhar sua vasta experiência e conhecimento sobre a prática do Projeto Político Pedagógico que, como supervisora de uma creche municipal, competentemente tem encaminhado junto ao coletivo da creche, em Florianópolis, SC.
} 


\section{Primeira conversa}

\section{Das Diretrizes Curriculares Nacionais ao cotidiano educativo: superar distâncias por meio do Projeto Político Pedagógico}

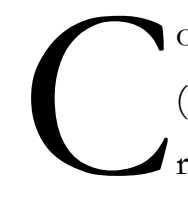

om a promulgação da Lei de Diretrizes e Bases da Educação Nacional (LDB), Lei no 9394/96 (BRASIL, 1996), todos sabemos que as especificidades das crianças de 0 a 5 anos foram reconhecidas e seu direito à educação afirmado, o que representou uma conquista. A partir de então, a Educação Infantil ficou definida como primeira etapa da educação básica. Além de princípios e determinações de ordem política e administrativa (financiamento, organização, profissionais, entre outros), a LDB também faz referência à elaboração e regulamentação das propostas pedagógicas, no caminho de concretizar o direito apregoado. O texto da lei expõe, no seu artigo 12: “Os estabelecimentos de ensino, respeitadas as normas comuns e as do seu sistema de ensino, terão a incumbência de: I elaborar e executar sua proposta pedagógica; [...]."; e continua, no artigo 13: “Os docentes incumbir-se-ão de: I - participar da elaboração da proposta pedagógica do estabelecimento de ensino; [...]" (BRASIL, 1996).

Importante chamar a atenção para o fato de a lei explicitar que ao conjunto de docentes caberá a participação do processo de elaboração da proposta pedagógica, rompendo com uma história de documentos verticalizados, impostos às escolas e instituições de Educação Infantil.

É neste espírito que as Diretrizes Curriculares Nacionais para a Educação Infantil (DCNEI), aprovadas em 1999 e revisadas em 2009, como documento de caráter mandatório, exigem a formulação, pelas instituições de Educação Infantil (entenda-se, por toda sua equipe profissional), de sua proposta pedagógica ou, como também vem sendo compreendido, de seu Projeto Político Pedagógico (PPP). Na publicação organizada pelo Ministério da Educação (MEC) para divulgação das DCNEI, encontramos as seguintes definições:

Proposta pedagógica ou Projeto Político Pedagógico é o plano orientador das ações da instituição e define as metas que se pretende para a aprendizagem e o desenvolvimento das crianças que nela são educados e cuidados. É elaborado num processo coletivo, com a participação da direção, dos professores e da comunidade escolar. (BRASIL, 2010, p. 13).

Para começo de conversa, a partir de tal definição, uma pergunta se impõe: para que elaborar um PPP na e pela instituição? Não raro, aqueles que estão, dia a dia, fazendo o cotidiano educativo em 
Creches e Pré-escolas se perdem por caminhos simplificados e desconexos, assumindo a escrita de um PPP como uma tarefa burocrática, destituída de significado. No atual momento histórico, em que vimos lutando por participação e democratização em todos os âmbitos da sociedade brasileira, inclusive na gestão educacional, tomar a elaboração de um PPP apenas como obrigação para cumprir as exigências legais seria descabido. Colocar-se à tarefa, tão somente porque é necessário apresentar aos órgãos competentes e fiscalizadores, como as Secretarias de Educação e Conselhos Municipais de Educação, correspondendo a uma incômoda formalidade, seria igualmente inaceitável.

Atitudes como essas podem ter por base a equivocada compreensão de que a existência da proposta pedagógica não faz a menor diferença para o funcionamento e andamento das funções desempenhadas pela instituição de Educação Infantil, uma vez que o mais importante é a prática. E assim, dicotomizando teoria e prática, resta apenas um destino ao famigerado PPP: tornar-se, como no dito popular, uma letra morta; um papel para ficar guardado na gaveta; e, justamente porque engavetado, desprezado, sem sentido.

Essa postura, muito comum, tem razões históricas. A tendência tecnicista que marcou a educação brasileira a partir dos anos 1970 é responsável, em certa medida, por concepções e práticas de planejamento educacional que ainda não fomos capazes de superar, as quais reduzem o ato de planejar a uma formalidade burocrática, em regra caracterizada pelo preenchimento de fichas e formulários com uma lista de objetivos, conteúdos e atividades, visando meramente o controle e a padronização do trabalho pedagógico que, à ação docente, nada acrescenta ou ajuda (OSTETTO, 2000).

Em uma concepção tecnicista, movida pela separação entre os atos de pensar e fazer, é tarefa de pessoal especializado a formulação de programas, currículos e planejamentos, sendo que aos educadores cabe-lhes apenas executarem o plano elaborado sem a sua participação. Como geralmente aquele pessoal especializado se mantém longe da escola, conclui-se sobre o distanciamento de suas proposições. De tal forma, guiados pelo manual, pelo livro, pela regra e não pela realidade particular de cada instituição educativa, os planejamentos ou propostas curriculares elaboradas nos gabinetes das secretarias de educação e afins acabam não correspondendo às necessidades daquela específica instituição e desrespeitam os saberes e as práticas docentes. Por isso não funcionam, tornam-se inadequados. Tipos de propostas com essas feições não oferecem real apoio para professoras e professores pensarem e agirem no seu cotidiano pedagógico, porque não dialogam com suas necessidades.

É assim que, sofrendo a pressão dessas marcas históricas, autoritárias e tecnicistas, muitas vezes o planejamento - seja do ensino, em particular, seja da proposta pedagógica, em geral - vira um peso para gestores e docentes. Equivocadamente compreendido como uma etapa do trabalho dispensável, transforma-se em um texto esvaziado de significado, com uma lista de objetivos e metas, um punhado de citações de autores "recomendáveis", com ares de fundamentação teórica, descolados e sem nada que ver com a realidade da instituição. Nessa direção, vão tão distantes seu significado e importância que poderia até ser copiado de outras instituições, ou, pior, reproduzido de modelos prontos, disponíveis na internet. 
Isso também acontece com a ideia e prática do Projeto Político Pedagógico, instrumento tão discutido nas últimas décadas (principalmente nas escolas) e que, justamente proposto em contraposição àquela tendência pedagógica, vem ganhando força em consonância com os novos tempos, de redemocratização da própria sociedade brasileira e da luta pela democratização da gestão escolar. Por isso, a tentativa de superar os resquícios do tecnicismo, que impõe à elaboração do PPP um ato puramente burocrático e, portanto, fragmentário, exige o exercício da reflexão, para que concepções e práticas possam ser identificadas, avaliadas e ressignificadas.

$\mathrm{Na}$ atualidade, urge nos apropriarmos desse instrumento como um espaço legítimo de participação e palco de disputas sobre projetos e concepções. Nessa perspectiva, é preciso assinalar que um Projeto Político Pedagógico:

[...] busca um rumo, uma direção. É uma ação intencional, com um sentido explícito, com um compromisso definido coletivamente. Por isso todo projeto pedagógico da escola é, também, um projeto político, por estar intimamente articulado ao compromisso sociopolítico com os interesses reais e coletivos da população. (VEIGA, 2010, p. 13).

É, portanto, instrumento orientador do trabalho da instituição, base e guia para o processo educacional a ser desenvolvido junto às crianças e à comunidade onde se localiza, dentro de um tempo e espaço definidos. No caso da Educação Infantil, coerentemente apontado pelas DCNEI, é instrumento imprescindível para qualquer instituição, seja Creche ou Pré-escola, período integral ou parcial, no centro ou na periferia, no campo ou na cidade.

Como um documento que sistematiza e organiza o trabalho coletivo das instituições que, ao defini-lo, afirmam a intencionalidade da prática pedagógica, não só aponta caminhos, mas prevê possibilidades de caminhar e construir o trabalho educativo, com todos. Afinal, não daria para seguir a jornada da Educação Infantil com as concepções pessoais que guiam cada professora, cada professor ou outro profissional da educação, individual e desarticuladamente. Há que ter uma direção geral, coletiva, comum a todos, que sustente e apoie o trabalho educativo da instituição como um coletivo.

Como documento de identidade, ele apresenta o perfil da instituição: declara seus objetivos e valores, define papéis, explicita modos de pensar as infâncias, as crianças e seus processos de conhecimento. É um documento que fala de um coletivo, de uma creche ou pré-escola: quem e como é essa instituição? E fala também dos desejos e das necessidades daqueles que cotidianamente fazem parte deste coletivo, tendo em comum as ações de cuidado e educação das crianças de zero a cinco anos: o que almejam, onde pretendem chegar, que caminhos querem seguir e por quê? Por isso também não dá para ser copiado. Diz respeito àquela, ou àquela outra, instituição. Identidade é coisa particular, não se repete, não se reproduz.

O Projeto Político Pedagógico, revelando a proposta pedagógica que a instituição realiza e que busca realizar, dando visibilidade a seus movimentos, seus desejos, seus objetivos, seu planejamento de diretrizes e metas, é o retrato da organização do trabalho pedagógico sonhado. 
No caso da Educação Infantil, lendo com atenção as DCNEI, percebe-se que os elementos a serem considerados no PPP estão claramente delineados: concepção de criança, concepção de Educação Infantil, eixos norteadores, princípios definidores. Esses seriam dados que, tal como uma carteira de identidade, todo PPP deve conter. Porém, esses princípios precisam ser conhecidos, apropriados pelos coletivos de Creches e Pré-escolas, para que sejam traduzidos em ação. Ler, estudar, debater, aprofundar conceitos assinalados com mediações teóricas outras é um bom começo para então seguir rumo à construção de uma proposta pedagógica com a marca e características de cada instituição.

Tal como o planejamento da prática pedagógica, a elaboração de um PPP só pode ter início mergulhando-se na realidade. É fundamental conhecer a instituição, sua dinâmica, sua organização, sua estrutura, suas características. E então, dentro dessa caracterização, refletir sobre suas conquistas e seus problemas, o que deve ser mantido, o que está respeitando os princípios das DCNEI, ou o que precisa ser modificado para atender com mais adequação aqueles princípios.

É preciso olhar para o cotidiano praticado, formulando perguntas e buscando respostas aos questionamentos, no coletivo, de modo que cada um e todos se vejam na identidade que vai sendo traçada à medida que a instituição se apropria de sua história. Por exemplo: onde se localiza a instituição de Educação Infantil, quem são as crianças que a frequentam, como são suas famílias e grupos de convívio? Como é seu espaço, como está constituída a rotina, como articulam o cuidar e o educar - que são objetivos indissociáveis da Educação Infantil - no cotidiano? Que mobiliários, que brinquedos, que materiais estão disponíveis marcando o jeito de fazer Educação Infantil da instituição? Como está configurada a organização pedagógica: como é o planejamento, como é a avaliação e o acompanhamento das crianças e de todo o processo pedagógico; professoras e professores fazem registros, há processos de documentação?

Apenas no movimento de desvelar o real (como diria Paulo Freire) é que a instituição poderá construir, de forma participativa e democrática, um PPP coerente, vivo, pleno de significado que oriente e aponte caminhos nos quais todos se percebam partícipes e, colocando-se de acordo, possam seguir redimensionando metas e objetivos que garantam a afirmação da criança, defendida nas DCNEI, como:

[...] sujeito histórico de direitos que, nas interações, relações e práticas cotidianas que vivencia, constrói sua identidade pessoal e coletiva, brinca, imagina, fantasia, deseja, aprende, observa, experimenta, narra, questiona e constrói sentidos sobre a natureza e a sociedade, produzindo cultura. (BRASIL, 2010, p. 12).

Essa concepção, é preciso ressaltar, corrobora a visão desenhada e afirmada nas últimas décadas, por debates, estudos e pesquisas em diferentes áreas, sobretudo no campo da Educação Infantil.

Para continuar a conversa, compartilho uma experiência de participação em um processo de elaboração do Projeto Político Pedagógico de uma creche pública. O coletivo de tal Creche (diretora, supervisora, docentes e demais profissionais) estava empenhado em rever seu PPP e foi então que me convidaram, como professora da universidade, para o diálogo, buscando apoio para a iniciativa. 
Certamente aquele coletivo não pretendia que eu fizesse o PPP para ele, mas que, no diálogo, pudesse dar pistas, clarear a visibilidade do caminho que estava pretendendo.

O ponto de partida para o processo desencadeado foi olhar para a história da creche, em toda sua complexidade: com que organização e com que práticas, regras, hábitos e atitudes se fez e se faz essa creche específica? Para tanto, sugeri o seguinte movimento: em pequenos grupos, listar como é a organização da creche. Pensando, por exemplo: como fazem a divisão/agrupamento das crianças; como é a rotina (os horários, as atividades); como é a alimentação, onde as crianças fazem as refeições, como fazem, se são servidas ou se elas próprias se servem dos alimentos; como é realizado o planejamento pedagógico; se elaboram registros diários, se documentam, como fazem; como está organizado o espaço da creche como um todo - interno e externo -, que cômodos existem, como são as salas de referência das crianças, o que existe de possibilidades no espaço físico para crianças e adultos, como é o mobiliário e como está disposto nos diferentes espaços/salas, que materiais estão disponibilizados, se há brinquedos, e quais são; como é a participação dos pais, através de que propostas as famílias são chamadas ou convidadas à participação; como é a ambientação (inserção, adaptação) das crianças novas à creche; como é a chegada diária das crianças e sua volta para casa, há algum encaminhamento ou organização especial; etc.

Depois de listada a dinâmica da creche nos seus vários aspectos, de dar visibilidade às práticas do cotidiano que sustentam sua existência, passou-se a analisar os dados levantados pelos pequenos grupos, seguindo alguns pontos: a maneira que temos organizado nosso cotidiano, está bem, funciona, dá conta da tarefa de educar e cuidar com qualidade (considera as especificidades etárias, emocionais, sociais; respeita as necessidades das crianças, seus direitos)? Está coerente com a visão apregoada pelas DCNEI? Ou seja, era chegado o momento de explicitar a identidade da creche construída e praticada ao longo dos anos, perceber conquistas e limites, acertos e equívocos, ganhos e perdas, presenças e faltas: o que é próprio da creche, o que pode ser mantido, o que precisa ser revisto e modificado? Momento, também, de aprofundar o debate em torno das questões mapeadas e trazidas para a discussão: que aspectos da vida da creche merecem maior atenção, quais foram identificados como fragilidade da creche, revelados como equívocos ou que requerem maior densidade teórica, para maior compreensão, que, inclusive, poderiam ser tomados como pontos para estudo.

Discutindo, refletindo, pensando o fazer para fazer melhor, como disse Paulo Freire (2013), podese seguir para, agora sim, projetar: traçar metas, definir objetivos. Assim, no caso da creche com a qual mantive o diálogo na experiência de revisão do seu PPP, foi identificado que o espaço das salas de referência dos grupos de crianças não estava permitindo a brincadeira, as trocas, a riqueza de interações entre elas. Então, para aquele ano, uma das propostas foi dar maior atenção ao papel da organização dos espaços, buscando subsídios para repensar a forma como vinham sendo organizados na creche. Aquele coletivo explicitou o desejo de experimentar modificar os espaços, pautando-se na reflexão teórica e, dessa forma, para viabilizar a ideia, foram previstas reuniões de estudo e planejamento ao longo do ano. Assim, 
a experiência compartilhada confirmou: no campo pedagógico, tudo é processo; o PPP é espaço de pesquisa, de investigação sobre os fazeres e saberes necessários à prática pedagógica.

Falei até aqui da dinâmica que sustentaria a elaboração de um PPP, com o intuito de colocar luz sobre um aspecto deveras importante: não é a palavra bonita, o conceito exato, segundo o autor A ou B, o texto rebuscado, cheio de citações da palavra alheia que está em questão. Mais uma vez lembro o mestre Paulo Freire (2013): é preciso dizer a sua palavra, com significado, expressão da experiência e da reflexão sobre a experiência, que é sempre informada por uma teoria. O essencial é que os sujeitos reais e concretos, que fazem a Educação Infantil, pronunciem a sua palavra, tomem a força e a beleza de sua própria voz, proferida com consciência e sensibilidade das coisas inteiras, pautada no compromisso com as crianças e com o seu próprio processo de formação. Quero dizer com isso que a forma, a sistematização da proposta em documento não poderá vir antes do debate, do diálogo, da análise das práticas e organização da instituição que está em processo de elaborar um PPP. Mas isso não quer dizer que não seja importante. É muito. Porém, a escrita vem depois do mergulho na memória, na história, na prática refletida; depois da análise dos dados recolhidos. Isto é, vem após a composição do retrato do percurso pedagógico que tem realizado.

Desse debate, do processo como um todo, é que o PPP como documento poderá ser sistematizado. A forma que ele assumirá é outra história. São muitas as maneiras de se articular em um texto as várias questões e os múltiplos aspectos discutidos no processo que vimos comentando.

Além de observadas as exigências das DCNEI, na organização de propostas pedagógicas para a Educação Infantil "devem também ser observadas a legislação estadual e municipal atinentes ao assunto, bem como as normas do respectivo sistema” (BRASIL, 2010, p. 11). Em seus estudos sobre o currículo na Educação Infantil, Faria e Salles (2010, p. 28), ponderam que “cada Conselho Estadual ou Municipal de Educação, ao regulamentar a Educação Infantil, define os aspectos que devem ser considerados na elaboração das propostas pedagógicas da Educação Infantil de seu sistema de ensino", sendo que os itens presentes na regulamentação normativa apresentado pelos órgãos legais podem se constituir em roteiro para que as instituições elaborem suas propostas. Porém, é sempre bom reforçar, como as próprias DCNEI definem, cabe às instituições formularem suas propostas pedagógicas e, nesse caso, respeitados os preceitos legais, poderão estruturá-las segundo suas necessidades, de maneira autônoma. Há que se fazer da elaboração/sistematização do PPP um momento de criação. Para isso eu dou um nome: autoria. As instituições (e chamo atenção especial ao coletivo docente) não podem abrir mão de um espaço que foi a duras penas conquistado! Não podem perder a oportunidade de colocar em debate ideias, concepções e fundamentos que incidirão sobre seu fazer cotidiano.

Sem entrar no mérito de qual a melhor forma de estruturar a proposta pedagógica, ou se haveria um roteiro básico para a escrita do texto, considero pertinentes os itens e a estrutura que as autoras referidas sugerem sejam contemplados:

História da instituição e sua Proposta Pedagógica. Contexto sociocultural no qual a instituição se insere concepções norteadoras do trabalho. Finalidades e objetivos. Organização e gestão do trabalho, que abrange: a) o currículo; b) os tempos; c) espaços, 
equipamentos e materiais; d) as crianças; e) as metodologias de trabalho; f) os instrumentos de trabalho do professor; g) os profissionais e suas condições de trabalho; h) o trabalho com a comunidade e com a família; i) as formas de articulação da Educação Infantil com o Ensino Fundamental; j) as formas de gestão institucional (FARIA; SALLES, 2010, p. 29).

Referente à gestão e organização do trabalho das instituições de Educação Infantil, é oportuno trazer à lembrança o que as DCNEI definem como currículo, um dos elementos que devem integrar uma proposta pedagógica, um PPP. O documento expõe claramente que currículo é um:

Conjunto de práticas que buscam articular as experiências e os saberes das crianças com os conhecimentos que fazem parte do patrimônio cultural, artístico, ambiental, científico e tecnológico, de modo a promover o desenvolvimento integral de crianças de 0 a 5 anos de idade (BRASIL, 2010, p. 12).

É importante destacar que o currículo é um componente da proposta pedagógica e, portanto, deve estar íntima e coerentemente articulado a ela. Jamais poderá ser pensando de forma isolada, nem se resumir a um quadro de conteúdos e objetivos, ou um conjunto de datas com atividades correspondentes, a serem seguidas e realizadas com as crianças, dia a dia, mês a mês. Nesse caso, há que se considerar o que está definido como eixos estruturantes de uma proposta pedagógica para a Educação Infantil: brincadeira e interação, articulados aos princípios mais amplos da ética, da política e da estética, tal como indicado nas DCNEI. Sobre esses aspectos falarei adiante.

Para finalizar esse primeiro item de nossa conversa, gostaria de lembrar que um decreto, uma norma, um documento, por sua mera existência não muda práticas, nem as qualifica. O que faz a mudança é a compreensão da sua importância, o sentido traduzido para a prática em forma de apoio, é a necessidade e o desejo daqueles que fazem a Educação Infantil acontecer, todo o dia, mês a mês, ano após ano. A localização da falta, a visibilidade da necessidade é que faz mover a busca, é que faz um documento tornar-se vivo, em movimento, junto com os saberes e fazeres dos professores e de todos os profissionais da creche, no caso específico. É preciso que as instituições tomem sua história na mão e tenham a coragem e ousadia de avaliar-se, para avançar. É imprescindível que assumam sua autoria, tomando o espaço do PPP também como um espaço de pesquisa. Afinal, o movimento do conhecimento é circular, não tem começo e não tem fim!

\section{Segunda Conversa}

\section{"O que isso quer dizer mesmo?": sobre os princípios éticos, políticos e estéticos}

São três os princípios que devem ser respeitados e contemplados nas propostas pedagógicas, segundo as DCNEI:

Éticos: da autonomia, da responsabilidade, da solidariedade e do respeito ao bem comum, ao meio ambiente e às diferentes culturas, identidades e singularidades. Políticos: dos direitos de cidadania, do exercício da criticidade e do respeito à ordem 
democrática. Estéticos: da sensibilidade, da criatividade, da ludicidade e da liberdade de expressão nas diferentes manifestações artística s e culturais. (BRASIL, 2010, p. 16).

Dia a dia ouvimos muito falar de ética, de política. De estética, um pouco menos. Mas, no contexto das DCNEI, o que isso significa mesmo? Essa foi a primeira pergunta que formulou uma professora, participante de um curso no qual eu dialogava sobre as DCNEI e seus princípios. Nesta questão levantada, a professora desvelou um limite para o alcance das diretrizes: a dificuldade em traduzilas em ação. Não basta estar escrito. É essencial interpretar, desvelar o conteúdo, aproximar-se dos ditos e não ditos, relacionar com o vivido. Apropriar-se. Para tanto, é fundamental a leitura do documento, o debate entre pares, a troca de ideias. Só entrando no texto pode-se trazer de lá significação, superando a aparente compreensão que acaba transformando-o em palavras vazias. Bonitas, mas esvaziadas de sentido.

$\mathrm{Na}$ sequência compartilho algumas reflexões sobre os princípios éticos, políticos e estéticos, buscando contribuir para a tradução de seus significados relacionados aos fazeres educativos. Pretendo, assim, estender pontes que ajudem a acessar seus, nem sempre evidentes, sentidos para a prática pedagógica.

\section{Princípios éticos: autonomia, responsabilidade, solidariedade, respeito, diferenças}

Há quanto tempo vimos falando, na Educação Infantil, na importância de se formar seres autônomos, curiosos e descobridores? No seu célebre apêndice $A$ autonomia como finalidade da educação: implicações da teoria de Piaget, já nos dizia Constance Kamii (1980, p.103) que "autonomia significa ser governado por si próprio. É o contrário de heteronomia, que significa ser governado por outrem”. Não estou me referindo aqui apenas à autonomia de as crianças cuidarem de si próprias, de seus objetos e pertences, ou de se servirem, na alimentação, de irem ao banheiro sozinhas, trocarem suas roupas. Quero falar também do aspecto moral da autonomia e, para tanto, valho-me da história contada pela referida autora:

Piaget deu exemplos comuns sobre a autonomia moral. Em suas pesquisas, perguntava às crianças de 6 a 14 anos se era pior dizer mentira a um adulto ou a outra criança. As crianças pequenas sistematicamente afirmavam que era pior dizer mentira a um adulto. Quando perguntadas - por quê? - explicavam que os adultos podem saber quando uma afirmação não é verdadeira. As crianças maiores, ao contrário, tendiam a responder que, algumas vezes, se sentiam forçadas a mentir para os adultos, mas que seria maldade fazê-lo com outras crianças. Este é um aspecto moral da autonomia. Para as pessoas autônomas, as mentiras são ruins, independentemente do fato das pessoas serem descobertas ou não. (KAMII,1990, p. 104).

As crianças pequenas manifestam sistematicamente a moralidade da heteronomia e vão se tornando progressivamente mais autônomas, embora, como adverte a pesquisadora piagetiana, nem sempre os adultos se tornam moralmente autônomos. Basta observarmos as notícias frequentes sobre os casos de corrupção, assassinatos e roubos em nossa sociedade. 
O importante a assinalar aqui, no que se refere ao papel da educação, é que "os adultos reforçam a heteronomia natural das crianças, quando usam recompensas e castigos, e estimulam o desenvolvimento da autonomia quando intercambiam pontos de vista com as crianças" (KAMII, 1990, p. 106).

A utilização de castigos e punições não contribui para o desenvolvimento da autonomia da criança e podem acarretar pelo menos três tipos de consequências no seu comportamento: cálculo de riscos, conformidade cega, revolta (KAMII, 1990). Também a recompensa reforça a heteronomia, uma vez que a criança fará a ação julgada correta apenas para ser merecedora de uma gratificação, submetendo-se aos ditames do adulto, justamente como aquela criança que corresponde às expectativas (sendo boazinha, por exemplo), apenas para não ser punida.

Retomei esse texto tão antigo (publicado originalmente na década de 1980), trazendo-o para a reflexão, pensando nas práticas ainda usuais na Educação Infantil, tais como "cadeira do pensamento", retirar o direito da criança ao tempo livre, ou à brincadeira, porque deixou de fazer isso ou aquilo, porque não obedeceu às ordens do professor, porque fez "bagunça" etc. Que procedimentos são esses? Nada mais são do que sutis punições, isolando a criança e submetendo-a a constrangimentos Este é o caminho da heteronomia. Pior, é o flagrante desrespeito aos princípios éticos da autonomia e do respeito, que devem reger as práticas na Educação Infantil, tal como determinado nas DCNEI.

Também é prudente assinalar, que trabalhar com e para a autonomia não significa cada um fazer o que quiser, mas fazê-lo para o bem do coletivo, considerando que minha ação interfere na ação do outro e no andamento do grupo; é saber-se responsável e comprometido com os acordos que sustentam a vida em grupo.

A essência da autonomia é que as crianças tornem-se aptas a tomar decisões por si mesmas. Mas a autonomia não é a mesma coisa que a liberdade completa. A autonomia significa levar em consideração os fatores relevantes para decidir agir da melhor forma para todos. Não pode haver moralidade quando se considera apenas o próprio ponto de vista. Quando uma pessoa leva em consideração os pontos de vistas das outras, não está mais livre para mentir, quebrar promessas e ser leviano. (KAMII, 1990, p. 108).

Trata-se de proporcionar às crianças oportunidades para ampliarem as possibilidades de aprendizado e de compreensão de mundo e de si próprias, ajudando-as a construir atitudes de respeito e solidariedade, fortalecendo os vínculos afetivos responsáveis pela ligação e integração de todas as crianças como um grupo.

A possibilidade de tomar uma decisão é o que distingue uma atitude do adulto como punição ou como oportunidade para a criança perceber a consequência de seu comportamento para a vida grupal. Sempre que o adulto oferece oportunidades para que a criança decida, incentiva o exercício da autonomia, de coordenação de pontos de vista - entre o seu e o do outro. Então, por exemplo, diante de uma situação em que a criança, à mesa de refeição, está visivelmente importunando os colegas que estão ao seu lado (não está comendo, mexe na comida tal como uma brincadeira, bate os talheres), o professor poderia simplesmente retirá-la da mesa, ou poderia dar-lhe o benefício da decisão, conversando com ela mais ou menos nestes termos: "Você está perturbando os colegas. Você poderá ficar almoçando aqui, sem todo 
esse barulho, ou ir para a sala fazer barulho lá". Isso é diferente de retirar a criança e decretar: "Você fez bagunça, está precisando pensar. Saia da mesa e vá para a cadeira do pensamento! ”.

Possibilitar que a criança tome uma decisão diante de um fato protagonizado por ela, tem a ver com o que Piaget chamou de "sanção por reciprocidade". Para compreendermos a diferença entre sansão e punição, cito a autora:

Privar uma criança da sobremesa por dizer mentira é um exemplo de punição, pois a relação entre mentira e sobremesa é completamente arbitrária. Mas dizer-lhe que não podemos acreditar nela é um exemplo de sanção por reciprocidade. As sanções por reciprocidade estão diretamente relacionadas com o ato que se deseja sancionar e com o ponto de vista do adulto, tendo o efeito de motivar a criança a construir por si mesma, regras de conduta através da coordenação de pontos de vista. (KAMII, 1990, p. 109).

É prudente chamar a atenção para o fato de que essa atitude do adulto pode facilmente escorregar para o autoritarismo, pois depende do grau de interação, dos vínculos construídos e da identidade já estabelecida entre eles. O próprio Piaget advertira que as sanções poderiam:

[...] degenerar em punições se não houvesse uma relação de afeto e respeito mútuos entre $\mathrm{O}$ adulto e a criança. O respeito mútuo é, de fato, essencial para o desenvolvimento da autonomia da criança. A criança que se sente respeitada em sua maneira de pensar e sentir é capaz de respeitar a maneira como os adultos pensam e sentem. (KAMII, 1990, p. 11).

Trabalhar para a construção de uma visão de mundo e de conhecimento plurais, cultivando atitudes de solidariedade e de respeito às diferenças, contra preconceitos, requer que professoras e professores não tomem os castigos e punições, mesmo que "brandas", como regra de conduta para conquistar a disciplina e a ordem (o famigerado "domínio de classe"), considerando-os naturais. No atual momento histórico, em que os direitos das crianças estão pautados, dentro e fora das instituições de ensino, é inconcebível que haja docentes que ainda utilizem a "cadeira do pensamento", o "canto para refletir". Com todas as letras: utilizar-se de tais expedientes é punir as crianças, é feri-las em seu direito básico à dignidade e ao respeito. No contexto particular das DCNEI, é descumpri-la em seus princípios éticos.

Garantir, acolhendo, a manifestação de necessidades, interesses e desejos das crianças, contribuindo para a construção de sua autoimagem positiva, reforçando sua autoestima e crença em suas capacidades de aprendizado e convívio social, é também parte deste princípio, que poderá se efetivar valorizando as produções, individuais e coletivas das crianças, em todos os âmbitos.

\section{Princípios políticos: direitos, deveres, participação, grupo, cidadania}

A dimensão política nos faz lembrar de direitos e deveres, de cidadania e participação. No âmbito da Educação Infantil, de sua prática pedagógica, pressupõe pensar na organização de um espaço livre de coerção, um cotidiano em cuja dinâmica as crianças possam se manifestar em toda sua inteireza: sentimentos, pensamento, intuição, múltiplos sentidos. Um ambiente que favoreça a formulação de 
perguntas e em que as dúvidas sejam acolhidas. Toda criança tem direito a se contrapor, a argumentar, a propor caminhos diversos daqueles propostos pelo professor, pela professora e pela instituição no seu conjunto; tem direito a apresentar ideias revelando seus modos próprios de ser e se expressar, respondendo aos desafios colocados no processo educativo, junto ao coletivo.

Aqui se traduz, no meu entender, a concepção de criança capaz, competente, que tem desejos e necessidades, que questiona a ordem circundante, não se submetendo às imposições de professoras e professores, simplesmente porque são adultos. Não uma criança passiva, que espera, espera, espera, espera a voz de comando a mandar o que fazer, a exigir a disciplina do silêncio, a direcionar verticalmente o caminho a seguir.

Claro está que a criança não pode tudo. Mas nem o adulto pode tudo. A dimensão política da proposta pedagógica nos faz lembrar de direitos e deveres, como já assinalei. A questão é: como cultivar um e outro? Como, enquanto docente, não cair no autoritarismo, nem no permissivismo, criticados por Paulo Freire (2011)? O desafio é, pois, constituir a autoridade, no cultivo de relações horizontais, onde todos tenham seu tempo e espaço. Onde desejos e necessidades são acolhidos, por meio de instrumentos e dinâmicas que organizam, que permitem negociações de posições, traduzidas em combinados que funcionam como regras do grupo, instituídos pelo próprio grupo (FREIRE, 1983). Caminhos para a autonomia, da qual falava anteriormente, como conteúdo dos princípios éticos. Não é deixar as crianças livres de qualquer intervenção, mas também não é controlá-las. É trabalhar a identidade individual e coletiva, o espírito de grupo, comprometidos com a busca do bem-estar coletivo e individual.

Nessa direção, em um trabalho que considere os princípios políticos enunciados, será importante cultivar relações dialógicas (FREIRE, 2011, 2013), o que pressupõe, fundamentalmente, ouvir as crianças. É imprescindível aprender a escutá-las, considerando importante tudo o que têm a dizer - em gestos, balbucios, palavras, movimentos, brincadeira. É sobre isso que fala Carla Rinaldi (2012, p. 124), ao se referir a uma "pedagogia da escuta":

Como definir o termo escuta? Escuta como sensibilidade aos padrões que conecta, ao que nos conecta aos outros [...] como metáfora para a abertura e a sensibilidade de ouvir e ser ouvido - ouvir não somente com as orelhas, mas com todos os nossos sentidos (visão, tato, olfato, paladar, audição e também direção). Escuta das cem, das mil linguagens, símbolos e códigos que usamos para nos expressar e nos comunicar, e com os quais a vida expressa a si mesma e se comunica com aqueles que sabem ouvir.

A escuta é, então, como já dissera Paulo Freire (2011, 2013), o ponto de partida para qualquer relação educativa. No nosso caso, no contexto da Educação Infantil, poderíamos dizer que é na dialogicidade da relação, que é escuta e troca de pontos de vista, sentidos e sentimentos, que a criança aprende a se posicionar, constrói opinião e aprende a respeitar a opinião dos outros. Exercita, assim, a dimensão cidadã de sua inserção no mundo.

Princípios estéticos: liberdade de expressão, sensibilidade, criatividade, ludicidade 
Quando se fala em estético, é comum nos reportarmos ao campo artístico. Porém, o sentir estético, natural a nossa espécie, não está relacionado exclusivamente à arte, mas "converte-se em uma forma de investigar, uma chave de interpretação, um lugar de experiência” (VECCHI, 2013, p. 65).

Nessa direção, contemplar os princípios estéticos "da sensibilidade, da criatividade, da ludicidade e da liberdade de expressão nas diferentes manifestações artísticas e culturais" (BRASIL, 2010, p. 16), como apregoados nas DCNEI, implicará pensar na organização de uma proposta que envolva um conjunto de vivências e experiências abertas à validação de outros modos de conhecer, qualificando sensibilidade, sentimento e intuição. Não descartar o estranho, o incompreensível, o inexplicável e, sobretudo, reconhecer as diferenças e validar a pluralidade de saberes e fazeres.

Para avançarmos na conversa e entendimento sobre a dimensão estética que deve permear e orientar a formulação das propostas pedagógicas, lembremos algumas práticas presentes no cotidiano de creches e pré-escolas: desenhos prontos para colorir; modelos de trabalhinho para reproduzir; datas comemorativas com suas lembrancinhas; folhinhas impressas para a "tarefinha de casa"; exercícios de prontidão, como seguir e completar desenhos e letras pontilhados; separação rígida entre hora de brincar e hora de atividades; salas decoradas com imagens advindas da indústria cultural, pobres em seus elementos composicionais e reproduzindo estereótipos (o mundo das princesas da Disney é uma clássica presença nas paredes de creches e pré-escolas!).

Detendo-nos nessas práticas, pensemos: correspondem a elementos incluídos nos princípios estéticos estabelecidos pelas DCNEI, como sensibilidade, criatividade, ludicidade e liberdade de expressão? Podemos nos demorar diante da questão posta. Respirar. Voltar a ler o rol de atividades listadas. E então? O que vemos? O que nos dizem? No confronto práticas-princípios, em que medida estão conectados, em que medida se relacionam com coerência?

Para que as propostas encaminhadas no dia a dia contribuam para o desenvolvimento e ampliação das capacidades expressivas das crianças, para sua educação estética, é preciso confiar em seu processo e possibilitar-lhes escolhas. Pois, como nos diz Ana Angélica Albano (2006, p. 17): "Criar é dar forma ao caos e para criar é preciso poder fazer escolhas. A escolha é o limite que cria a forma. Só aprendemos a escolher o próprio caminho, quando temos liberdade de opção". E para contemplar essa liberdade, potencializando os processos criadores, é imprescindível ter "[...] confiança no processo do outro, na sua capacidade de propor ideias, de usar os materiais de forma responsável para dar forma ao invisível, falando com as imagens o que as palavras não dizem" (ALBANO, 2006, p. 17).

Quando oferecemos às crianças a reprodução de desenhos para colorirem, é como se estivéssemos dizendo-lhes: "Não confiamos em você. Tome um modelo e assim você fará como deve ser feito!". E isso, claro está, fere os princípios de sensibilidade, criatividade, ludicidade e liberdade de expressão, estabelecidos nas DCNEI. Para guardar coerência, traduzindo aqueles princípios para o fazer pedagógico, a direção a ser tomada será outra: antes de propor, é essencial acompanhar, dialogar, escutar, como já assinalado. 
Quanto mais professoras e professores estiverem disponíveis para acompanhar as crianças na sua curiosa expedição de reconhecimento e interação com tudo que as cerca, dando valor para as coisas que procuram, pegam, experimentam, dizem, inventam, propõem, tanto mais poderão pensar e encaminhar situações que alimentem seu processo criativo, que enriqueçam o desenvolvimento de suas linguagens. Tanto mais seguirão pelas veredas do princípio estético, respeitando-o.

Para viabilizar tudo isso será necessário dar tempo e planejar os ambientes para as experiências das crianças; implicará validar e abrir espaço para as culturas infantis, ou seja, para o que as crianças fazem, pensam e sentem sobre o mundo a sua volta, sobre a vida, num movimento interdependente de produção de significados e possibilidades de tecer sua própria vida.

Nesse sentido, também não podemos aceitar práticas balizadas pelo consumo, fazendo uso de objetos, imagens e referências midiáticas, marcas de uma cultura massificada, que rouba o espaço da individualidade, da autoria, incentivando a cópia e a reprodução de modelos, pois "A arte se define justamente pela diversidade, por propor algo que é pessoal e único. Quando se aceita esta premissa, temos que descartar toda atividade que tenha como ponto de partida a uniformidade" (ALBANO, 2002, p. 84).

E, não esqueçamos, até o espaço físico informa a perspectiva estética: suas paredes falam - às vezes denunciam... o descaso, a mesmice, o consumismo. A decoração nunca é apenas um enfeite, um detalhe para deixar a sala e os ambientes mais bonitinhos. É texto que dá direção para o olhar e o pensamento daqueles que habitam um determinado espaço. É um potente elemento de educação visual (CUNHA, 2005). O que pareceria uma inofensiva e delicada princesa, é um decisivo direcionamento dos sentidos, mobilizando discursos aparentemente inexistentes. É um elemento de educação estética.

Imaginemos uma sala decorada nas cores rosa e azul, sendo que na parte rosa estão os nomes das meninas e na parte azul os nomes dos meninos. Simples decoração? Não. Há um discurso sendo informado por essa "ornamentação" da sala, que revela questões de gênero, dentro das quais as cores têm sexo. Quem disse que azul é de menino e rosa é de menina?

Da mesma forma poderíamos refletir sobre os personagens do mundo encantado da Disney que tão comumente povoam os espaços da Educação Infantil, com seus príncipes e suas princesas. Princesinhas delicadas, frágeis, com seus belos e longos cabelos loiros... Mais do que imagens que enfeitam, são textos visuais que portam significados (CUNHA, 2005) e, sutilmente, dizem de uma certa imagem de mulher. Além do que, imaginemos, a classe é repleta de meninas afrodescendentes. Assim, uma decoração só com princesas de pele e cabelos claros, não permite àquelas crianças referências para a constituição de sua identidade. Onde estão as figuras, desenhos e imagens de negros enfeitando as salas e os ambientes de creches e pré-escolas, para que essas meninas possam se ver refletidas? Esse aspecto está intimamente ligado aos outros dois princípios, pois vemos claramente as dimensões éticas, políticas e estéticas se revelando.

Nesse ponto poderemos chamar atenção para outro aspecto contido nas DCNEI: a questão da diversidade. Vale ressaltar seu conteúdo, citando o documento: 
As propostas pedagógicas das instituições de Educação Infantil deverão prever condições para o trabalho coletivo e para a organização de materiais, espaços e tempos que asseguram: o reconhecimento, a valorização, o respeito e a interação das crianças com as histórias e as culturas africanas, afro-brasileiras, bem como o combate ao racismo e à discriminação [...]. (BRASIL, 2010, p. 21).

Entre os princípios estéticos definidos nas DCNEI, está a "liberdade de expressão nas diferentes manifestações artística e culturais” (BRASIL, 2010, p. 16), já citada no início de nossa conversa sobre esse item. Há, portanto, que criar espaços para que as manifestações da cultura africana e afro-brasileira também apareçam no cotidiano educativo. E não será, por certo, apenas fazendo um "projeto de trabalho" com o tema da diversidade. Não. A educação estética, assim como a educação das relações étnico-raciais, não acontece em dias marcados, em uma lição, em uma atividade. É uma tarefa cotidiana, contínua, envolvendo todos os aspectos organizacionais: tempos, espaços (e, neles, a decoração), atividades, materiais, brinquedos.

\section{Terceira conversa}

\section{Dos eixos norteadores às linguagens no cotidiano educativo: possibilidades}

As interações e a brincadeira são apontadas nas DCNEI como eixos norteadores do currículo, por consequência, considera-se que as práticas pedagógicas deverão garantir uma diversidade de experiências que contemplem tais eixos.

A brincadeira já é, em si, momento propício às interações. Geralmente as crianças se reúnem para brincar, chamam umas às outras, ou vão se agregando no decorrer das ações, dos enredos que estão sendo construídos por uma ou um grupinho delas. Mas a brincadeira não é inata, como inicialmente poderíamos pensar. Aprende-se a brincar. Não por meio de um aprendizado aos moldes da escola do ABC, com o adulto ensinando passo a passo como, quando, onde devem brincar. Não. As crianças aprendem no contexto, brincando, entrando no jogo. Aprende-se a brincar desde a mais tenra idade, nas relações que meninos e meninas, homens e mulheres, estabelecem com os outros e com a cultura ao longo da vida.

A criança pequena é iniciada na brincadeira por quem cuida dela. Num primeiro momento, quando bem pequenina, é o adulto que brinca com ela. Progressivamente, vai entrando na brincadeira do adulto: primeiro como expectadora ativa, depois como real parceira (BROUGÈRE, 1995). Pouco a pouco vai aprendendo a compreender, dominar e produzir uma situação específica, distinta de outras - a brincadeira -, que supõe a capacidade de considerar uma ação de um modo diferente: "O que diferencia o primeiro momento (não brincar) do segundo momento (brincar), é a intenção da criança" (KISHIMOTO, 1994, p. 5). A brincadeira é uma atividade, por excelência, que permite desenvolver a iniciativa infantil.

Como forma particular e desenvolvida de atividade lúdica, a brincadeira implica representação de papéis sociais. Enquanto brinca, a criança comporta-se de forma mais avançada do que nas atividades da vida real, trabalha com representações mentais: a criação de uma situação imaginária pode ser considerada 
como um meio para desenvolvimento do pensamento abstrato. Afinal, brincadeira é mutação de sentido: as coisas aí se tornam outras, por exemplo, fazer de um pedaço de madeira um carro, de um tubo de plástico um trem (KISHIMOTO, 1994; BROUGÈRE, 1995; WAJSKOP, 1995).

E o brinquedo? O brinquedo é o objeto que pode desencadear a brincadeira (e depois ser seu mediador e suporte) (WAJSKOP, 1995), por isso a importância de disponibilizar não apenas brinquedos estruturados, com funções definidas e fixas, mas também de oferecer materialidades variadas, que sugiram manipulação ativa, construir e desconstruir, montar e desmontar; isto é, uma gama de materiais e objetos que podem se constituir em brinquedo, que possam ser transformados (madeirinhas, panos, tampinhas, caixas, potes etc.), porque estão abertos à significação das crianças enquanto brincam.

Brincar supõe a existência de tempos e espaços disponíveis. Se a criança brinca é porque há tempo ao seu dispor. Pensar a brincadeira no cotidiano da Educação Infantil é, portanto, pensar no tempo para brincar (WAJSKOP, 1995). Por isso, garantir contextos que favoreçam a brincadeira entre as crianças, que ofereçam oportunidades para explorarem diferentes materiais em suas histórias e construírem enredos fantásticos, viajando por mundos e territórios imaginários, exige o planejamento e a organização de espaços e tempos.

Se as DCNEI dizem que a brincadeira é um eixo norteador do currículo, não é possível pensarmos em termos de se planejar a "hora de brincar", como se houvesse coisa mais importante que a brincadeira, feito a "hora do recreio" das escolas, momento em que a energia da criança se expande da cabeça para o corpo inteiro. Se a brincadeira é eixo, deve ser a atividade central do planejamento pedagógico.

Quanto aos espaços, é preciso prever, organizar em diversas partes, nas áreas internas e externas, lugares desafiadores para o desenvolvimento de brincadeiras. Professoras e professores potencializam a brincadeira e as interações quando preparam um ambiente que convide ao lúdico, às descobertas e à diversidade de enredos e relações entre as crianças. A estruturação do espaço possibilita roteiros para as crianças organizarem suas brincadeiras. Dependendo do que está disponível no ambiente, as crianças se movimentam, criam e recriam as situações de suas brincadeiras. A colocação, num canto da sala, de fogão, pia, utensílios de cozinha, mesa e cadeiras, por exemplo, está sugerindo um roteiro para o desenvolvimento da brincadeira de casinha: cozinhar, comer, lavar, e assim por diante. Se, mais tarde, for introduzido nesse espaço um cabide com roupas penduradas, certamente as crianças poderão ampliar o roteiro inicial: além de lavar, cozinhar, comer, agora podem também "trocar" de roupa e, talvez, sair para passear na casa da comadre, depois de ter feito um bolo. Pode ser que não aconteça isso, pois aí está a riqueza do espaço e tempo da brincadeira: depende das escolhas das crianças, e as possibilidades de enredos são infinitas.

O espaço criado deve, também, ser ao mesmo tempo seguro, limpo e confortável, propiciando tanto o movimento quanto o recolhimento. Afinal, nem sempre todas as crianças desejam, e precisam, estar umas com as outras. Elas também têm direito a estarem sós, recolhidas com "seus botões", histórias 
e sentimentos. Poderão ser pensados cantos e recantos em que, com segurança, as crianças possam se "isolar".

Porém, não basta garantir materiais e brinquedos adequados e espaços organizados. É indispensável a presença de um adulto atento e sensível para transformar os espaços da Educação Infantil em ambientes nos quais a ludicidade seja sua marca registrada. No que se refere à brincadeira, em especial, é fundamental a observação atenciosa de professoras e professores, porque ao observarem de que forma, como e onde as crianças estão brincando, poderão levantar dados, fazer um inventário, sobre os conhecimentos que estão envolvendo as crianças, sobre seus interesses, sobre os temas que as estão mobilizando.

A estruturação do espaço possibilita roteiros para as brincadeiras, como fiz notar anteriormente. Então, por exemplo: em determinada situação a professora, ou o professor, presencia a criança levando a boneca para lavar no pequeno baú que estava no canto da sala. Naquele espaço não havia lugar estruturado para a ação de dar banho nas bonecas. Esse roteiro não foi pensado, mas a criança criou. $\mathrm{O}$ adulto que está atento à movimentação dessas crianças brincando, poderá introduzir no espaço um objeto que possa ser utilizado de banheira, ou chuveiro, para que nas próximas brincadeiras as crianças possam também se beneficiar dessa estruturação que sugere banhos, no caso do exemplo apresentado. Isso vai enriquecer os enredos, pode ajudar a complexificar as relações vivenciadas na brincadeira.

A brincadeira é eixo estruturador da proposta pedagógica, mas ela não é toda a proposta. Outras e variadas situações e atividades devem permear o cotidiano educativo, permitindo às crianças o desenvolvimento de sua capacidade de representação, como o trabalho com outras linguagens, com a expressão plástica, por exemplo. Porém, é importante assinalar, seja na brincadeira ou em outros momentos, o essencial é que professoras e professores estejam disponíveis e atentos ao que as meninas e os meninos estão fazendo, pois é essa atitude que lhes possibilitará obterem mais informações sobre os processos das crianças, suas perguntas e descobertas. Assim, poderão recolher mais dados, ganhando subsídios para propor espaços e situações em que a criança seja autora de seus resultados, de suas produções. Possibilitar a descoberta de outros modos de ver e intervir no real, isso é o mais importante.

De outra forma, ouvir histórias, assistir filmes, sair para passeios, frequentar museus, podem funcionar como atividades complementares à brincadeira, enriquecendo-a. São atividades que não são brincadeiras, mas podem contribuir com os temas que aparecem dentro das brincadeiras das crianças. Desenvolver outras atividades enriquece a atividade lúdica. Por exemplo, depois de um passeio à central de recolha e separação do lixo reciclável da cidade, as crianças passam a brincar de catadores, separando o "lixo bom", e até criam um ateliê de criação a partir do lixo catado. O tema expandiu-se pela escolha das próprias crianças, e será tanto mais ampliado se o roteiro evidenciado por elas for acolhido, oferecendolhes mais elementos, materiais e espaços organizados, para que a brincadeira ocorra. Porém, nunca daquela maneira escolarizada, chamando as crianças: "que tal fazermos como na central de lixo que visitamos? Vocês viram aquelas esculturas construídas com potes e papéis coloridos descartados? Vamos criar um objeto com o lixo recolhido?". Isso seria didatizar a brincadeira, deixando de ser brincadeira, portanto. 
Brincadeira é brincadeira, os roteiros são feitos pelas crianças e não podem jamais ser dirigidos pelo adulto. Historicamente vimos (e vemos ainda), tentativas de escolarizar a brincadeira, utilizando-as como pretexto para ensinar determinados conteúdos, retirando o seu caráter de brincadeira, a qual pressupõe escolha, prazer, frivolidade, liberdade (BROUGÈRE, 1995; WAJSKOP, 1995).

A pesquisadora Ângela Borba (2006), discutindo sobre a presença e os sentidos da brincadeira no Ensino Fundamental e na Educação Infantil, convida-nos a refletir sobre práticas muito comuns no cotidiano pedagógico, como as músicas utilizadas para memorização de hábitos, atitudes e informações. Diz a autora, que certas práticas, quando compreendidas

[...] apenas como recursos, perdem o sentido de brincadeira e, muitas vezes, até mesmo o seu caráter lúdico, assumindo muito mais a função de treinar e sistematizar conhecimentos, uma vez que são usados com o objetivo principal de atingir resultados preestabelecidos. (BORBA, 2006, p. 43).

Inclusive, como adverte Lydia Hortélio (2008, p. 25), "não se deve brincar para aprender"; "brincar é o maior exercício de liberdade que a gente pode ter". Não é a pretensão de ensinar e aprender que move a brincadeira e a sua importância dentro e fora da escola e da Educação Infantil. Na sua sabedoria e conhecimento de grande brincante, a pesquisadora das cantigas, brinquedos e brincadeiras do Brasil nos conta:

Deve-se brincar para ser feliz. Se você quiser brincar para aprender já não é mais brinquedo. Porque o brinquedo tem um fim nele mesmo. Bola pra quê? Pra brincar de bola. Você brinca de peteca pra quê? Pra brincar de peteca, para passar pela experiência múltipla e extraordinária que é brincar de peteca. E por que brincar de roda? Porque é uma maravilha: mão na mão, esquecer quem é você, embarcar no sonho daquela hora... Brincar é isso aí. Mas há quem queira transformar o brinquedo num "brinquedo pedagógico"... Existem tentativas nesse sentido, mas não dá, porque há uma incongruência. (HORTÉLIO, 2008, p. 25).

Ao tratar dos eixos do currículo, podemos ler no texto das DCNEI que as propostas pedagógicas também devem garantir múltiplas experiências que:

Favoreçam a imersão das crianças nas diferentes linguagens e o progressivo domínio por elas de vários gêneros e formas de expressão: gestual, verbal, plástica, dramática e musical; [...] Promovam o relacionamento e a interação das crianças com diversificadas manifestações de música, artes plásticas e gráficas, cinema, fotografia, dança, teatro, poesia, literatura; [...] Propiciem a interação e o conhecimento pelas crianças das manifestações e tradições culturais brasileiras; [...]. (BRASIL, 2010, p. 25-27).

Para continuar nossa conversa, a partir de tais indicações (que para mim estão relacionadas aos princípios estéticos), abro outro ponto para discussão: as diferentes linguagens na Educação Infantil, também contempladas pelas DCNEI, como citado acima. Começo por dizer que contemplar as linguagens em projetos pedagógicos na Educação Infantil implica a construção de um pensar-fazer estruturado sobre a premissa da necessidade de se apresentar desafios às crianças, ao contrário da simples proposição de trabalhinhos isolados para executarem, aguardando a resposta já prevista ou esperando um resultado padronizado. Estamos num campo que dialoga com a arte, em que a palavra de ordem é criação. Falar de 
diferentes linguagens é falar de busca, imaginação, fruição, liberdade de expressão, pesquisa, experiência: criança e criação não podem ser fixadas - são experimentação, com todos os sentidos.

Há um fenômeno notório: a Educação Infantil (quiçá como herança da escola) ainda insiste em didatizar os processos e vivências com a arte e a cultura em geral. Apresenta modelos, estabelece regras, mostra passo a passo como se faz. É tão comum o desenho pronto para colorir, não? Uma tristeza. Dessa forma, controla, aprisiona o que só pode existir livremente, em sua fluidez de processo contínuo. Rouba, para utilizar uma expressão de Loris Malaguzzi (1999) em seu famoso poema, a alegria do processo, da invenção, da vida, enfim.

A regra e a repetição de modelos são estranhas ao processo criador, à aprendizagem e ao desenvolvimento das linguagens artísticas e expressivas. Trabalhar com as múltiplas linguagens, com a arte, é abraçar a incerteza, dialogar com diferentes materialidades, colocar a mão na massa, provar todos os sentidos, saborear o gosto do mistério, investigar possibilidades, entregar-se à novidade e não temer a aventura do desconhecido. Do contrário, seria reduzir suas possibilidades, empobrecer a experiência potencial das crianças - que a todo tempo, nas suas invenções de modas e histórias, dizem para a gente que tudo é muito mais. São cem, são mil e uma possibilidades de conhecer e expressar o mundo.

De outro modo, valorizar o processo, focar na experiência acontecendo, não é deixar a criança a sua própria sorte, como quem pensa "ela deve fazer do seu jeito". Não podemos cair no espontaneísmo, na improvisação, sinônimos de falta de intencionalidade. É preciso estar atento ao instante que causa maravilhamento, que solicita e movimenta todos os sentidos da criança se envolvendo com as materialidades, objetos e espaços tal qual um pesquisador. Os resultados, em termos de produto, são secundários, importam menos. Isso porque, quando as crianças estão entretidas com algum objeto ou material, manuseando, mexendo, construindo, desconstruindo, rabiscando, pintando, melecando, não estão criando obrigatoriamente uma obra de arte. Como coloca a artista e arte-educadora dinamarquesa Anna Marie Holm (2007, p. 14, grifo da autora), estão criando “algo próprio, que está além disso", algo que está além da ordem do visível e quantificável. Ou seja, a principal transformação está acontecendo internamente, no seu corpo, no seu pensamento.

Pode-se concluir que o pensamento criativo se encontra no processo desencadeado pela experimentação, por meio da qual a criança faz e se faz: ela não apenas manipula, junta e transforma materiais, mas também transforma e produz ideias, sentimentos e significados simbólicos na atividade (FERREIRA, 2013)

Nesse caso, propor para a criança um carimbo do pezinho ou da mãozinha, daquela forma como comumente se faz (pegando cada criança individualmente, pincelando tinta no pé ou na mão, conforme a ocasião, e carimbando sobre um papel pardo ou cartolina, levando logo em seguida a criança para lavar a tinta que restou na parte pintada de seu corpo), não tem o menor sentido para a criança. Só um adulto cego às necessidades, características de desenvolvimento e desejos de um bebê poderá considerar esse tipo de procedimento uma atividade interessante e artística! Tal proposta responde apenas ao anseio deste adulto que, assim, pensa justificar sua ação profissional docente ou, então, deseja "ter algo" para mostrar 
aos pais, principalmente em se tratando de bebês, tão pequenos, que "nem sabem desenhar ainda". Esses procedimentos didáticos são o que tenho chamado de automatismos pedagógicos, realizados de maneira mecânica, sem a pausa necessária para a reflexão, sem ouvir e ver os movimentos de meninas e meninos, sem se importar com a direção de seus olhares curiosos.

Vamos pensar: por que ver a criança pequena pelo que ela ainda não consegue fazer? Por que impor aos bebês, por exemplo, atividades nas quais são conduzidos, controlados? Seria mais significativo, e na mesma medida mais importante para seu desenvolvimento e aprendizagem, o contato, o toque, o manuseio, a exploração de diferentes matérias e suas qualidades. É tempo de exploração, não necessariamente de construção.

As atividades nessa fase devem ter como objetivo proporcionar uma variada gama de experiências sensoriais que permitam ampliar o conhecimento que a criança tem do ambiente e de sua capacidade de agir sobre os objetos. Precisam manusear diferentes materiais explorando suas qualidades: o macio e o áspero, o grande e o pequeno, o quente e o frio etc. Explorar várias possibilidades de riscar, marcar, modelar, pintar em diferentes superfícies: chão, madeira, papelão, tecido, areia, cimento, terra. (ALBANO, 2010, p. 59 , grifos da autora).

Para tanto, é necessário que professoras e professores deixem de lado concepções e práticas já cristalizadas a respeito do que seja uma "atividade pedagógica", determinando tempo e lugar "para ensinar" (arte ou outra área de conhecimento). O planejamento pedagógico é a base para a atuação docente, é o horizonte de um caminho que pretende percorrer com o grupo de crianças, que marca sua intencionalidade e compromisso educativos, mas não se resume a uma listagem de atividades a serem realizadas (OSTETTO, 2000). Muitas vezes, uma proposta é encaminhada e, no percurso, as crianças vão para lados opostos, demonstrando outros focos de curiosidade. O que fazer? Se professoras e professores estiverem prestando atenção as suas manifestações, verão indicações - na expressão, no gesto, no balbucio, no movimento, na fala das crianças -, de novas possibilidades para continuarem a história inicial, que a partir da escuta poderá se multiplicar em tantas outras.

\section{Quarta conversa}

\section{As linguagens e a brincadeira de professoras e professores: resgate necessário}

Como se fora brincadeira de roda. No meio de toda essa história estamos nós, professoras e professores, que também sofremos interdições na nossa ação de sonhar e inventar mundos - seja nas brincadeiras, no desenho, na dança, na música, na leitura de uma história. Nossas linguagens e possibilidades expressivas também foram reprimidas. E então, o que acontece? Não raro, temos dificuldade em respeitar e valorizar nas crianças suas formas de conhecer, dizer e representar o mundo. $\mathrm{O}$ encontro festivo entre um grupinho de crianças, que imagina situações e tira prazer do momento compartilhado, fazendo alarde, habitualmente é tomado como bagunça. 
Escondemos nosso ser brincante, nos esquecemos das brincadeiras, de viajar na imaginação, de inventar histórias. Já não brincamos! Resulta que, se o adulto não recuperar sua dimensão imaginativa e descobridora, dificilmente poderá oferecer instrumentos que nutram e ampliem o jogo metafórico que engendra os universos infantis, cultivando sensibilidade, cognição e afeto. Para seguir alimentando processos criativos e criadores com as crianças na Educação Infantil, é imprescindível que professoras e professores saiam em busca, se aventurem por caminhos dantes não percorridos, ampliando sensibilidades e olhares no encontro com o outro, com a cultura. É indispensável redescobrir sentidos - o que lhes encanta, o que lhes mobiliza, o que lhes emociona, que fazeres e saberes foram deixando ao longo do caminho da criança que foram, aos adultos que são hoje? (OSTETTO; LEITE, 2004).

Para respeitar as possibilidades expressivas e criadoras de meninos e meninas, contribuindo com o cultivo e a ampliação das mesmas, precisam estar conectados com a sua expressão, precisam reconquistar o seu poder imaginativo. No livro que tem por título $O$ espaço do desenho: a educação do educador, publicado em 1984, Ana Angélica Albano discutia a centralidade da sensibilidade no trabalho com crianças, e indicava que a formação docente deveria passar, necessariamente, pelo reencontro do espaço lúdico dentro de si, pela redescoberta das suas linguagens, do seu modo de dizer e expressar o mundo. A autora falava da essencialidade de arriscar novos olhares, "reaprendendo a ver, a se espantar com o que vê" (ALBANO, 2002, p.95).

As palavras da década de 1980 ainda hoje reverberam e nos impulsionam a reafirmar: professoras e professores são pessoas-chave para mediar os caminhos da criança no mundo simbólico da cultura, compreendendo que, no percurso da experiência, na disposição em se colocar no lugar do outro-criança para compreendê-lo, reconhecê-lo e apoiar suas buscas e escolhas, também se movimentam por universos criadores e universos criados - na ciência e na arte, uma e outra, marcas do humano (OSTETTO, 2007). Brincando, imaginando, ousando novos passos e atitudes, podem seguir para além do instituído, inventando jeitos de ver e expressar o mundo, recuperando beleza para o cotidiano da Educação Infantil e inteireza para a prática pedagógica e para a vida. Como diz Lydia Hortélio (2008, p. 23), na sua sabedoria da experiência de brincante, "É preciso brincar para afirmar a vida"! 


\section{Referências}

ALBANO, A. A. O espaço do desenho: a educação do educador. 9. ed. São Paulo: Loyola. 2002.

ALBANO. A. A. O atelier e a caixa de Pandora. Revista Projeto Sementinha, Santo André, SP, p.16-18, 2006.

ALBANO, A. A. Pensando as artes visuais na educação. In: GONÇALVES, T. F.; DIAS, A. R. Entre linhas, formas e cores: arte na escola. Campinas, SP: Papirus, 2010. p.49-63.

BORBA, A. M. O brincar como um modo de ser e estar no mundo. In: BRASIL. Ministério da Educação. Ensino fundamental de nove anos: orientações para a inclusão da criança de seis anos de idade. Brasilia, DF: FNDE; Estação Gráfica, 2006. p. 33-45.

BRASIL. Lei no 9.394, 20 de dezembro de 1996. Estabelece as diretrizes e bases da educação nacional. Diário Oficial da União, Brasília, DF, 23 dez. 1996.

BRASIL. Ministério da Educação. Secretaria de Educação Básica. Diretrizes Curriculares Nacionais para a Educação Infantil. Brasília, DF: MEC/SEB, 2010.

BROUGÈRE, G. Brinquedo e Cultura. São Paulo: Cortez, 1995.

CUNHA, S. R. V. da. Um pouco além das decorações das salas de aula. Reflexão e Ação, Santa Cruz do Sul, v. 13, n. 1, p. 133-149, jan./jun. 2005.

FARIA, V.; SALLES, F. Currículo na Educação Infantil: diálogos com os demais elementos da proposta pedagógica. São Paulo: Scipione, 2010. p. 19-42.

FERREIRA, P. N. O espírito das coisas: desenho, assemblages e brincadeiras na Educação Infantil. Maceió: EDUFAL, 2013.

FREIRE, M. A paixão de conhecer o mundo. Rio de Janeiro: Paz e Terra,1983.

FREIRE, P. Pedagogia da autonomia: saberes necessários à prática educativa. Rio de Janeiro: Paz e Terra, 2011.

FREIRE, P. Cartas à Cristina: reflexões sobre minha vida e minha práxis. 3. ed. Rio de Janeiro: Paz e Terra, 2013.

HOLM, A. M. Baby-art: os primeiros passos com a arte. São Paulo: Museu de Arte Moderna de São Paulo, 2007.

HORTÉLIO, L. É preciso brincar para afirmar a vida. Almanaque de cultura popular: Revista de bordo da TAM, São Paulo, n. 114, p. 23-25, out. 2008.

KAMII, C. A autonomia como finalidade da educação: implicação da teoria de Piaget. In: KAMII, C. A criança e o número. Campinas, SP: Papirus, 1990. p. 103-124.

KISHIMOTO, T. M. O jogo e a Educação Infantil. São Paulo: Pioneira, 1994. 
MALAGUZZI, L. Ao contrário, as cem existem. In: EDWARDS, C. et al. As cem linguagens da criança: a abordagem de Reggio Emilia na educação da primeira infância. Porto Alegre: Artes Médicas, 1999.

OSTETTO, L. E. O planejamento pedagógico na Educação Infantil: mais que a atividade, a criança em foco. In: OSTETTO, L. E. (Org.) Encontros e encantamentos na Educação Infantil. Campinas, SP: Papirus, 2000. p. 175-200.

OSTETTO, L. E. Entre a prosa e a poesia: fazeres, saberes e conhecimento na Educação Infantil. In: PILLOTTO, S. S. D. (Org.). Linguagens da arte na infância. Joinville, SC: Univille, 2007. p. 29-45.

OSTETTO, L. E.; LEITE, M. I. Arte, infância e formação de professores: autoria e transgressão. Campinas, SP: Papirus, 2004.

RINALDI, C. Diálogos com Reggio Emilia: escutar, investigar e aprender. São Paulo: Paz e Terra, 2012.

VECCHI, V. Arte y creatividad en Reggio Emilia: el papel de los talleres y sus posibilidades en educación infantil. Madrid: Morata, 2013.

VEIGA, I. P. A. (Org.). Projeto político-pedagógico na escola: uma construção possível. 28. ed. Campinas, SP: Papirus, 2010. p. 11-35.

WAJSKOP, G. Brincar na pré-escola. São Paulo: Cortez, 1995. 